\title{
Corrigendum to "Quality characteristics, chemical composition, and sensory properties of butter from cows on pasture versus indoor feeding systems" (J. Dairy Sci. 99:9441-9460)
}

\author{
Tom F. O'Callaghan, Hope Faulkner, Stephen McAuliffe, Maurice G. O'Sullivan, Deirdre Hennessy, \\ Pat Dillon, Kieran N. Kilcawley, Catherine Stanton, and R. Paul Ross
}

We would like to bring to the attention of readers errors reported in the above article. In particular, 2 sets of peaks that were eluting close together were reported in reverse order because of an issue with the GC standard preparation. The fatty acids $\alpha$-linolenic acid (C18:3n-3; ALA) and eicosenoic acid (C20:1 cis-11) were labelled in reverse order, as were behenic acid (C22:0) and eicosatrienoic acid (C20:3n-6). $\gamma$-Linoleic acid (C18:3n-6 cis) has been removed. Although values for these fatty acids and the calculations that include them are affected, the overall trend for these have not changed, and each is still significantly higher than or correlated with the same feeding systems with the exception of behenic acid. The changes primarily alter the results section of the paper and the study's conclusions remain unchanged. In addition to changes in the text, Table 1 and Figure 1 have been corrected. Overall, we feel that the findings and conclusions of the paper remain valid and demonstrate the effect of cows' feeding system on the fatty acid composition of butter. The authors regret the errors.

A revised version of this paper containing the corrections noted above has been published as supplementary data (see file below). An additional supplemental file (Corrections) indicates the exact changes made in text, table, and figure.

\section{REFERENCES}

O'Callaghan, T. F., H. Faulkner, S. McAuliffe, M. G. O'Sullivan, D. Hennessy, P. Dillon, K. N. Kilcawley, C. Stanton, and R. P. Ross. 2016. Quality characteristics, chemical composition, and sensory properties of butter from cows on pasture versus indoor feeding systems. J. Dairy Sci. 99(12):9441-9460. https://doi.org/10.3168/jds.2016-11271. 